\title{
Drugs for the treatment of hypercalcaemia
}

\author{
C. R. PATERSON \\ M.A., D.M., M.R.C.PATH. \\ Department of Clinical Chemistry, University of Dundee, Dundee
}

\begin{abstract}
Summary
Hypercalcaemia is ordinarily treated by treatment of the underlying disorder. In some cases, as in malignant disease, in vitamin $D$ poisoning and after a failed parathyroidectomy, the hypercalcaemia itself needs to be treated. A large number of methods have been advocated for this, but phosphate is the drug of choice in most patients. This paper outlines its use, mode of action and side effects and reviews the other methods proposed for the management of hypercalcaemia.
\end{abstract}

\section{Introduction}

The management of hypercalcaemia is ordinarily that of the underlying disorder (Wills, 1971; Henrard, 1971; Watson, 1972). There are, however, some circumstances when the hypercalcaemia itself must be treated; in severe life-threatening hypercalcaemia and in hypercalcaemia whose cause cannot be rectified. Examples of these include the hypercalcaemia of malignant disease and that of vitamin D poisoning which may persist for some months after the vitamin is withdrawn. In both of these instances treatment of the hypercalcaemia usually leads to a worthwhile improvement in symptoms.

Some authors advise a low calcium diet as part of the management of hypercalcaemia. While the avoidance of excess calcium in the diet is reasonable, it is doubtful whether (apart from in idiopathic hypercalcaemia of infancy) a low calcium diet contributes enough to justify the effort. All but the mildest cases of hypercalcaemia tend to be dehydrated and this should be corrected. In addition a number of therapeutic measures have been advocated; none is ideal and it is important to recognize their indications and limitations.

\section{Phosphate}

Phosphate therapy is the most widely studied method for the control of hypercalcaemia and can be administered orally or intravenously. Oral phosphate is given as a mixture of phosphates to have a neutral $\mathrm{pH}$ and a suitable preparation is now avail-

Correspondence: Dr C. R. Paterson, Department of Clinical Chemistry, Ninewells Hospital, Dundee, DD2 1UD able commercially (Phosphate Sandoz). The initiat dose is $1-3 \mathrm{~g}$ (of phosphorus) per day according 18 the size of the patient. The serum calcium should be checked daily at first and the dose adjusted appre. priately so that the maintenace dose is the minimuin consistent with control of the serum calcium. Oris phosphate therapy is effective in the management of hypercalcaemia of malignant disease and myelomi (Goldsmith and Ingbar, 1966; Goldsmith et a o $^{\circ}$ 1968; Thalassinos and Joplin, 1968), in hyperpara thyroidism (Dent, 1962; Goldsmith and Ingbar, 1966; Eisenberg, 1968), and in vitamin D poisoning (Goldsmith and Ingbar, 1966).

Intravenous phosphate therapy is used in the management of acute hypercalcaemia, especiallo in the patient who is vomiting or in coma. The for lation of Goldsmith and Ingbar (1966) calls feg $0 \cdot 1 \mathrm{M}$ solution containing in 1 litre $0.081 \mathrm{~mole}(11.50 \mathrm{~g}$ of $\mathrm{Na}_{2} \mathrm{HPO}_{4}$ and 0.019 mole $(2.59 \mathrm{~g})$ of $\mathrm{KH}_{2} \mathrm{PO}$ Such a solution should have a pH of 7.4 and 1 litre wi provide $3.1 \mathrm{~g}$ of phosphorus, $162 \mathrm{mEq}$ of sodium an $19 \mathrm{mEq}$ of potassium. In the first instance $500 \mathrm{ml}$ of this should be given slowly over at least $8 \mathrm{hr}$ and the patient should be carefully observed. In particular the serum calcium should be measured during and after the infusion, to check for hypocalcaemia. these tests are not available, electrocardiographi recordings are helpful. The infusion may be repeated after $24 \mathrm{hr}$ but should not be repeated if there evidence of a rising blood urea, oliguria or as elevated serum phosphorus more than $24 \mathrm{hr}$ afte the infusion (Fulmer et al., 1972). Intravenous phos phate therapy is very effective in reducing the serum calcium and may lead to a rapid improvement in the very ill patient with severe hypercalcaemia. It should however be replaced by oral therapy as soon $\$$ possible and it is probably safer to undertreat thatrs to overtreat.

\section{Side effects}

Oral phosphate has few reported side effect Some patients develop diarrhoea but this is usually temporary and may be relieved by the omission of one or two doses. More serious is the possibility of extra-skeletal calcification. Dudley and Blackburi 
(1970) observed patients treated with oral neutral phosphate for from 9 to 87 months. Six out of nine patients had conjunctival calcification demonstrated by slip-lamp examination, five had radiological evidence of extra-skeletal calcification, and two had progressive renal impairment. Other authors (Thalassinos and Joplin, 1968; Kistler and Neubauer, 1970) found little evidence of extra-skeletal calcification except in patients with previous severe hypercalcaemia. Furthermore in most patients renal function improves with phosphate therapy so that it seems likely that treatment with phosphate is less damaging to the kidney than the hypercalcaemia itself. One patient with hyperparathyroidism had oral phosphate therapy for 13 years with only a very slow deterioration in renal function (Stamp, 1971).

Hypocalcaemia is seldom seen with careful oral phosphate therapy but a combination of calcitonin and oral phosphate has caused hypocalcaemia (Parsons et al., 1970). A rise in the serum phosphorus occurs in some of the patients, particularly those with malignant disease who have a high serum phosphorus before treatment. These are probably the patients in whom caution is indicated to avoid extra-skeletal calcification if treatment has to be prolonged.

Intravenous phosphate therapy has been associated with more serious side effects (Suki et al., 1970). There are case reports of hypotension, massive extra-skeletal deposition of calcium, acute oliguric renal failure and death. Some of these cases have been patients in whom excessive doses have been used and hypocalcaemia has been caused. In addition some of the patients with side effects were already dangerously ill with the hypercalcaemia or with the neoplastic disease itself. Most workers have used cautious phosphate infusions without difficulty (Stamp, 1971; Fulmer et al., 1972).

\section{Mode of action}

The mode of action of phosphate therapy is not well understood. The excretion of calcium in the urine decreases and it is thought that calcium phosphate salts are deposited in soft tissue and bone (Hebert et al., 1966). Studies on rats and rabbits have suggested that extensive and damaging soft tissue calcification may occur with oral phosphate therapy (Spaulding and Walser, 1970; Jowsey and Balasubramaniam, 1972). However after phosphate has been used in patients with hypercalcaemia there is little evidence of soft tissue calcification in those who subsequently came to autopsy (Thalassinos and Joplin, 1968). Furthermore there is now chemical and kinetic evidence that even in rats the principal site of the calcium deposition is the bone (Feinblatt, Bélanger and Rasmussen, 1970; Haddad and Avioli, 1970).

\section{Sodium sulphate}

Intravenous infusions of sodium chloride and sodium sulphate both reduce the serum calcium in patients with hypercalcaemia but sodium sulphate appears to be more effective (Chakmakjian and Bethune, 1966). Either salt causes increased sodium excretion which itself increases urine calcium output but sodium sulphate therapy is additionally effective because unreabsorbable calcium sulphate complexes are formed in the urine.

Sodium sulphate therapy appears to be remarkably safe. Nausea occurs in a few patients especially if the infusion is rapid. Sodium overload has been described (Heckman and Walsh, 1967) and sodium sulphate is clearly contra-indicated in patients with renal failure or poor cardiac reserve. Hypokalaemia is often seen but may be prevented by the addition of a small proportion of potassium sulphate to the intravenous fluid. Hypomagnesaemia is also possible.

Practical details of sodium sulphate therapy are given by Walser (1970) who regarded sulphate as the method of choice for the management of severe hypercalcaemia. I do not share this view because sodium sulphate must be given intravenously, requires very large volumes of fluid and is less effective than phosphate (Fulmer et al., 1972).

The use of sodium sulphate by mouth has been reported on one occasion. It is effective in reducing the serum calcium but it causes severe diarrhoea (Kowarski et al., 1961).

\section{Frusemide}

Frusemide and ethacrynic acid promote calcium excretion as well as sodium excretion. If large intravenous doses of frusemide are given, and the sodium, potassium and water losses replaced, this becomes a method for lowering the serum calcium although not all patients respond and a normal serum calcium is not achieved in all those who do (Suki et al., 1970; Humbert et al., 1972; Baguet et al., 1972). This treatment is contraindicated in renal failure and as very large volumes of intravenous fluid are needed careful monitoring of fluid, sodium, potassium and magnesium balances is needed. A bed scale is valuable if available.

There is little place for this form of therapy: it is not uniformly effective; its control requires constant attention which may be impractical in some emergencies; its effectiveness diminishes after a few days (Toft and Roin, 1971) so that it is unlikely to be of any value in longer-term management.

\section{Chelating agents}

Sodium ethylene diamine tetra-acetate (sodium edetate, sodium EDTA) is a chelating agent with a powerful avidity for calcium and heavy metals. 
Given intravenously it binds calcium and the calcium-EDTA complexes are excreted in the urine. Disadvantages of this method are that it must be given intravenously, that each infusion has a transient effect and that its control calls for estimation of the serum calcium fraction not bound to EDTA. The appropriate compleximetric titration methods for calcium estimation are not widely available. In addition there have been reports (Dudley et al., 1955) of renal damage after EDTA therapy and this treatment has fallen into disuse.

\section{Corticosteroids}

In several studies steroid therapy has been thought to be of value in the management of hypercalcaemia of all causes other than hyperparathyroidism. A good response to large doses (hydrocortisone $120 \mathrm{mg}$ daily in divided doses) is usually seen with vitamin $\mathbf{D}$ poisoning, sarcoidosis and the milk-alkali syndrome. Steroids are of course effective in the rare hypercalcaemia of adrenal insufficiency. In the much more common problem of hypercalcaemia of malignant disease its value is more controversial. Good responses have been seen in perhaps $50 \%$ of these patients, in a better proportion of patients with myeloma or breast carcinoma, but in no more than $20 \%$ of patients with pseudohyperparathyroidism (Kessinger, Lemon and Foley, 1972). In recent series phosphate has been found to be much more consistently effective than steroids in the management of hypercalcaemia of malignancy (Thalassinos and Joplin, 1970; Fulmer et al., 1972). Short courses of steroid therapy are effective in the very rare hypercalcaemias of immobilization (Lawrence et al., 1973).

The mode of action of corticosteroids in hypercalcaemia is not well understood. In vitamin D poisoning, steroids reduce the excessive intestinal absorption of calcium (Favus, 1970). In myeloma and other malignant disorders which do respond to steroids, steroids reduce bone resorption (Lazor and Rosenberg, 1964; Muirhead, 1967).

The dangers of long-term therapy with steroids are well known. In the short-term, steroids are slow in action and several days are needed for a worthwhile response. For these reasons steroid therapy probably has at best a small role in the present-day management of hypercalcaemia.

\section{Mithramycin}

Mithramycin is an antibiotic with cytotoxic activity; like actinomycin $\mathrm{D}$ it appears to act by the inhibition of RNA synthesis (Yarbro, Kennedy and Barnum, 1966). In clinical use in neoplastic disease hypocalcaemia has been noted and more recently the place of mithramycin in the management of hypercalcaemia has been explored. In most patients with severe hypercalcaemia due to malignant disease a single intravenous injection of mithramycin $\left(25 \frac{2}{2}\right.$ $\mu \mathrm{g} / \mathrm{kg}$ ) is followed by a gradual fall in serum calcium $\stackrel{2}{c}$ toward normal values over $48 \mathrm{hr}$ (Slayton et al., $\stackrel{\leftrightarrow}{\longrightarrow}$ 1971; Elias, Reynoso and Mittelman, 1972; Elias $\stackrel{\vec{\sim}}{\circ}$ and Evans, 1972). At the same time there is a fall in serum phosphorus levels and in the urinary calcium $\overline{0}$ excretion. Mithramycin has also been effective in $\frac{\overline{\bar{F}}}{\overline{0}}$ reducing the serum calcium in a few patients with $\overparen{\otimes}$ hyperparathyroidism (Perlia et al., 1970; Singer et al., 1970). The hypocalcaemic action of mithramycin probably results from an inhibition of bone resorp- $\vec{\circ}$ tion perhaps by antagonism to the action of vitamin D.

The larger doses of mithramycin used in anti-क्ठ tumour therapy have been associated with nausea 3 and vomiting, with haematological disorders, with if liver and renal tubular damage and with skin changes. Much smaller doses are used in the management of $\infty$ hypercalcaemia and so far side-effects from these doses appear to be uncommon. Of sixty-nine patients ज $_{\infty}$ studied by Slayton et al. (1971) one had liver damage 음 and another bleeding due to thrombocytopaenia.

\section{Calcitonin}

Calcitonin has recently become available com- $\frac{\widehat{\Im}}{\mathcal{J}}$ mercially for the treatment of Paget's disease of borge $\vec{\theta}$ and also for the management of hypercalcaemia. $\$$ is certainly a valuable agent in certain patients wif Paget's disease and bone pains, but its place in the management of hypercalcaemia is less certain.

In hyperparathyroidism some patients have had a worthwhile response to calcitonin (West et al., 1971; 응 Hesch et al., 1971) but even in these normal values $\varrho$ are seldom achieved. Other patients have shown very $\overrightarrow{\overrightarrow{0}}$ modest responses to calcitonin (Sørensen et al., $Э$ 1970; Cochran et al., 1970; Hill, Ouais and Leiser, 1972). In the hypercalcaemia of vitamin $D$ intoxica-? tion a good, though slow, response to calcitonin was found in three patients by Buckle et al. (1972) although saline infusions may also have contributed $\frac{5}{3}$ to the improvement. Of two patients with vitamin $D_{-}$ poisoning and hypercalcaemia studied by West et al. 욱 (1971) one, a child, appeared to respond while an adult appeared to have gained no advantage from calcitonin. Objective assessment of the value of $\frac{D}{2}$ calcitonin in vitamin $\mathrm{D}$ poisoning is difficult as there may be great variations between patients in the rate $N_{O}$ at which the serum calcium falls after stopping the vitamin $D$. In the hypercalcaemia of malignant 0 disease a partial or complete response was noted in $\omega$ most of the patients studied by Silva and Becker (1973). In two patients with thyrotoxic hypercalcaemia calcitonin may have contributed to an $\mathbb{D}$ improvement in the serum calcium although normal ${ }_{+}^{+}$ values were not achieved and other therapy was used in addition (Sørensen et al., 1970; Buckle, Mason and Middleton, 1969). 
Most workers have used a dose of 4-8 MRC units/ $\mathrm{kg} /$ day by intramuscular injection although Silva and Becker gave $8 \mathrm{MRC}$ units/kg every $6 \mathrm{hr}$. There is as yet no good evidence that the intravenous route has any advantage over intramuscular therapy. Calcitonin is probably inappropriate in the longterm treatment of hypercalcaemia as it must be given parenterally and as resistance to its action, ascribed to antibody development, has been described (Singer et al., 1972).

Calcitonin appears to have few side effects although nausea and vomiting may occur with higher doses. There is a possibility of a reaction to the foreign material and an intradermal test should be done especially in patients with a history of allergy. Hypocalcaemia has not been described as a result of treatment with calcitonin alone.

\section{Mode of action}

In some studies the response to calcitonin seemed to be better related to the bone turnover rate than to the degree of hypercalcaemia and it seems likely that the main action of calcitonin is an inhibition of bone resorption (Haddad and Avioli, 1970). In addition there may be a small diminution of renal tubular reabsorption of calcium as an increase in calcium excretion is noted in some patients (Buckle et al., 1969; Cochran et al., 1970).

\section{Oestrogens}

Oestrogens inhibit parathormone-induced bone resorption (Atkins et al., 1972) and may have a place in the medical management of some post-menopausal women with mild hyperparathyroidism. Gallagher and Nordin (1972) obtained a modest reduction in the serum calcium (though not into the normal range) in a group of these patients.

In one patient with intractable hypercalcaemia from parathyroid carcinoma, stilboestrol diphosphate was effective in reducing the serum calcium when other measures had failed (Sigurdsson et al., 1973).

Oestrogens may precipitate or worsen the hypercalcaemia in some patients with carcinoma (Muirhead, 1967).

\section{Dialysis}

There are very few case reports of the use of dialysis in the control of hypercalcaemia and even in these there is no unanimity about its value. Haemodialysis has been used in a hypercalcaemic emergency as a means of buying time (Eisenberg and Gotch, 1968). Peritoneal dialysis with calcium-free solutions has been effective in a case of vitamin $D$ poisoning (Nolph, Stolz and Maher, 1971).

\section{Conclusions}

In most cases of hypercalcaemia (especially in malignant disease and after failed parathyroidectomy for hyperparathyroidism), oral phosphate is the treatment of choice. It is effective and appears to be reasonably safe. In patients who are vomiting or unconscious, intravenous phosphate should be used, but the treatment should be changed to phosphate by mouth as soon as it is practical. Renal failure is not a contra-indication to phosphate therapy but the potassium salt may need to be replaced by sodium in the infusion.

In the hypercalcaemias of sarcoidosis and immobilization, steroid therapy is probably the method of choice. In vitamin D poisoning there is no information on the relative merits of steroid therapy and phosphate which are both effective. However, in my view, oral phosphate is probably preferable to longterm steroid therapy. Apart from these three disorders steroid therapy is seldom indicated.

The place of calcitonin is difficult to define. It should be of value in a patient with Paget's disease in whom immobilization cannot be avoided. Apart from this there are no clear indications for it at present. It is expensive and must be given parenterally. Sodium sulphate is of doubtful value because it is less effective than phosphate. Frusemide, too, is not uniformly effective in controlling hypercalcaemia and its use requires very elaborate monitoring. Dialysis has been tried too seldom to allow any opinion of its value; it should never be necessary.

In hypercalcaemia resistant to phosphate therapy mithramycin should be used. If this fails, as in very occasional patients with parathyroid carcinoma, stilboestrol diphosphate is perhaps worth a trial.

\section{Acknowledgment}

I am indebted to Dr Peter Down for his helpful criticism.

\section{References}

Atkins, D., Zanelli, J.M., Peacock, M. \& Nordin, B.E.C. (1972) The effect of oestrogens on the response of bone to parathyroid hormone in vitro. Journal of Endocrinology, 54, 107.

Baguet, J.-C., Rampon, S., Bussière, J.-L., Sauvezie, B., Gontier, Y., Flori, B., Doly, J., NeURy, N. \& JANNY, P. (1972) Traitement de l'hypercalcémie aiguë par le furosémide. Revue du Rhumatisme, 39, 531.

Buckle, R.M., Mason, A.M.S. \& Middleton, J.E. (1969) Thyrotoxic hypercalcaemia treated with porcine calcitonin. Lancet, i, 1128.

Buckle, R.M., Gamlen, T.R. \& Pullen, I.M. (1972) Vitamin D intoxication treated with porcine calcitonin. British Medical Journal, 3, 205.

Chakmakjian, Z.H. \& BeThune, J.E. (1966) Sodium sulfate treatment of hypercalcemia. New England Journal of Medicine, 265, 862.

Cochran, M., Peacock, M., Sachs, G. \& Nordin, B.E.C. (1970) Renal effects of calcitonin. British Medical Journal, $1,135$.

DENT, C.E. (1962) Some problems of hyperparathyroidism. British Medical Journal, 2, 1419, 1495. 
Dudley, F.J. \& BlaCkBurN, C.R.B. (1970) Extraskeletal calcification complicating oral neutral-phosphate therapy. Lancet, ii, 628.

Dudley, H.R., Ritchie, A.C., Schilling, A. \& BaKer, W.H. (1955) Pathologic changes associated with the use of sodium ethylene diamine tetra-acetate in the treatment of hypercalcaemia. New England Journal of Medicine, 252, 331.

EISENBERG, E. (1968) Effects of varying phosphate intake in primary hyperparathyroidism. Journal of Clinical Endocrinology and Metabolism, 28, 651.

EISENBERG, E. \& GoTCH, F.A. (1968) Normocalcemic hyperparathyroidism culminating in hypercalcemic crisis. Archives of Internal Medicine, 122, 258.

Elias, E.G. \& Evans, J.T. (1972) Hypercalcemic crisis in neoplastic diseases: management with mithramycin. Surgery, 71, 631.

Elias, E.G., Reynoso, G. \& Mittelman, A. (1972) Control of hypercalcemia with mithramycin. Annals of Surgery, 175, 431.

Favus, M.J. (1970) Treatment of vitamin D intoxication. New England Journal of Medicine, 283, 1468.

Feinblatt, J. Bélanger, L.F. \& Rasmussen, H. (1970) Effect of phosphate infusion on bone metabolism and parathyroid hormone action. American Journal of Physiology, 218, 1624.

Fulmer, D.H., Dimich, A.B., RothsChild, E.O. \& MYers, W.P.L. (1972) Treatment of hypercalcemia. Comparison of intravenously administered phosphate, sulfate and hydrocortisone. Archives of Internal Medicine, 129, 923.

Gallagher, J.C. \& Nordin, B.E.C. (1972) Treatment with oestrogens of primary hyperparathyroidism in postmenopausal women. Lancet, i, 503.

GolDSMITH, R.S. \& INGBAR, S.H. (1966) Inorganic phosphate treatment of hypercalcemia of diverse etiologies. New England Journal of Medicine, 274, 1.

GoldSmith, R.S., Bartos, H., Hulley, S.B., Ingbar, S.H. \& MoloneY, W.C. (1968) Phosphate supplementation as an adjunct in the therapy of multiple myeloma. Archives of Internal Medicine, 122, 128.

HADDAD, J.G. \& Avioli, L.V. (1970) Comparative effects of phosphate and thyrocalcitonin on skeletal turnover. Endocrinology, 87, 1245.

Hebert, L. A., Lemann, J., Petersen, J.R. \& Lennon, E.J. (1966) Studies of the mechanism by which phosphate infusion lowers serum calcium concentration. Journal of Clinical Investigation, 45, 1886.

HeckmaN, B.A. \& WALSH, J.H. (1967) Hypernatremia complicating sodium sulfate therapy for hypercalcemic crisis. New England Journal of Medicine, 276, 1082.

Henrard, J.-C. (1971) Les hypercalcémies. Presse Médicale, 79, 2023, 2285, 2373.

Hesch, R.-D., Hufner, M., PASChen, K. \& von ZUR Muhlen, A. (1971) Akute behandlung des hypercalcämischen hyperparathyreoidismus mit calcitonin. Deutsche Medizinische Wochenschrift, 96, 764.

Hill, C.S., Ouais, S.G. \& Leiser, A.E. (1972) Long-term administration of calcitonin for hypercalcemia secondary to recurrent parathyroid carcinoma. Cancer, 29, 1016.

Humbert, G., Fillastre, J.-P., Leroy, J., Robert, M. \& Delaunay, P. (1972) Les hypercalcémies aiguës: traitement par le furosémide. Nouvelle Presse Médicale, 1, 2025.

Jowsey, J. \& Balasubramaniam, P. (1972) Effect of phosphate supplements on soft-tissue calcification and bone turnover. Clinical Science, 42, 289.

Kessinger, A., Lemon, H.M. \& Foley, J.F. (1972) Hypercalcemia of malignancy. Geriat rics, $27,97$.

Kistler, H.J. \& Neubauer, W. (1970) Phosphatbehandlung bei hypercalcämie. Klinische Wochenschrift, 48, 741.

Kowarski, A., Shapiro, T.R., Biezunski, N. \& Kowarski, C. (1961) Hypervitaminosis D: effect of treatment with sodium sulfate. Pediatrics, 27, 1004.
LAWrence, G.D., Loeffler, R.G., Martin, L.G. \& Connor, T.B. (1973) Immobilization hypercalcaemia. Journal of Bone and Joint Surgery, 55-A, 87.

LAZOR, M.Z. \& RoSENBERG, L.E. (1964) Mechanisms of adrenal-steroid reversal of hypercalcaemia in multiple $\mathscr{S}$ myeloma. New England Journal of Medicine, 270, 749.

MuIRHEAD, W. (1967) Hormonal treatment of hypercalcaemia caused by bone metastases. Canadian Medical Association Journal, 97, 569.

NolPh, K.D., Stolz, M. \& MAHER, J.F. (1971) Calcium free peritoneal dialysis. Treatment of vitamin D intoxication. Archives of Internal Medicine, 128, 809.

Parsons, V., Parsons, V. Porter, A. \& Lund, C. (1970) An $\overrightarrow{0}$ acceptable slow-release phosphate preparation 'Slow P'. Postgraduate Medical Journal, 46, 417.

Perlia, C.P., Gubisch, N.J., Wolter, J., Edelberg, D., Dederick, M.M. \& TAYloR, S.G. (1970) Mithramycin treatment of hypercalcemia. Cancer, 25, 389.

Sigurdsson, G., Woodhouse, N.J.Y., TAYLOR, S. \& Joplin, G.F. (1973) Stilboestrol diphosphate in hypercalcaemia or due to parathyroid carcinoma. British Medical Journal, 1, ¿ 27.

Silva, O.L. \& BeCKer, K.L. (1973) Treatment of hypercalcemia with synthetic salmon calcitonin. Archives of $\vec{G}$ Internal Medicine, 132, 337.

Singer, F.R., NeEr, R.M., Murray, T.M., Keutmann, H.T., 은 Deftos, L.J. \& PotTs, J.T. (1970) Mithramycin treatment of intractable hypercalcemia due to parathyroid carcinoma. New England Journal of Medicine, 283, 634.

Singer, F.R., Aldred, J.P., NeER, R.M., KRANe, S.M., PotTs, J.T. \& BLOCH, K.J. (1972) An evaluation of antibodies and clinical resistance to salmon calcitonin. Journal of Clinical Investigation, 51, 2331.

Slayton, R.E., Shnider, B.I., Elias, E., Horton, J. \& Perlia, C.P. (1971) New approach to the treatment of hypercalcemia. The effect of short-term treatment wit mithramycin. Clinical Pharmacology and Therapeutics, 12, 833.

Sørensen, O.H., Fris, T., Hindberg, I. \& Nielsen, S.P. (1970) The effect of calcitonin injected into hypercalcaemic and normocalcaemic patients. Acta Medica Scandinavica, 187, 283.

SPAUlding, S.W. \& Walser, M. (1970) Treatment of experimental hypercalcemia with oral phosphate. Journal of Clinical Endocrinology, 31, 531.

Stamp, T.C.B. (1971) The hypocalcaemic effect of intravenous phosphate administration. Clinical Science, 40, 55.

Suki, W.N., Yium, J.J., Von Minden, M., SAller-Hebert, C., Eknoyan, G. \& Martinez-Maldonado, M. (1970) Acute treatment of hypercalcemia with furosemide. New 3 England Journal of Medicine, 283, 836.

Thalassinos, N. \& JoPlin, G.F. (1968) Phosphate treatment of hypercalcaemia due to carcinoma. British Medical Journal, 4, 14.

Thalassinos, N.C. \& Joplin, G.F. (1970) Failure of corticosteroid therapy to correct the hypercalcaemia of malignant disease. Lancet, ii, 537.

ToFT, H. \& RoIN, J. (1971) Effect of frusemide administra- $\mathrm{N}$ tion on calcium excretion. British Medical Journal, 1, 437. ఠ

WALSER, M. (1970) Treatment of hypercalcaemias. Modern $\mathrm{N}$ Treatment, 7, 662 .

WATSON, L. (1972) Diagnosis and treatment of hypercal- $\mathcal{W}$ caemia. British Medical Journal, 2, 150.

WeSt, T.E.T., JofFe, M., Sinclair, L. \& O'RioRdan, J.L.H. (1971) Treatment of hypercalcaemia with calcitonin. Lancet, i, 675.

WILLS, M.R. (1971) Disorders of calcium homeostasis British Journal of Hospital Medicine, 6, 65.

YarbRo, J.W., KENNEDY, B.J. \& BARNUM, C.P. (1966) Mithramycin inhibition of ribonucleic acid synthesis. Cancer Research, 26, 36. 